trol in patients with mild asthma. ${ }^{5}$ A goal of clinical investigation should be to provide new information and a firm scientific rationale from which to devise the next set of guidelines.

Stephen P. Peters, M.D., Ph.D.

Wake Forest University

Winston-Salem, NC 27157

Mario Castro, M.D.

Washington University

St. Louis, MO 63110-1093

Janet T. Holbrook, M.P.H., Ph.D.

Johns Hopkins University

Baltimore, MD 21205

jholbroo@jhsph.edu
1. Haahtela T, Jarvinen M, Kava T, et al. Effects of reducing or discontinuing inhaled budesonide in patients with mild asthma. N Engl J Med 1994;331:700-5.

2. Hawkins G, McMahon AD, Twaddle S, Wood SF, Ford I, Thomson NC. Stepping down inhaled corticosteroids in asthma: randomised controlled trial. BMJ 2003;326:1115-20.

3. Nelson HS, Weiss ST, Bleecker ER, Yancey SW, Dorinsky PM. The Salmeterol Multicenter Asthma Research Trial: a comparison of usual pharmacotherapy for asthma or usual pharmacotherapy plus salmeterol. Chest 2006;129:15-26. [Erratum, Chest 2006;129:1393.]

4. Masoli M, Weatherall M, Ayling J, Williams M, Beasley R. The $24 \mathrm{~h}$ duration of bronchodilator action of the salmeterol/fluticasone combination inhaler. Respir Med 2005;99:545-52.

5. Boushey HA, Sorkness CA, King TS, et al. Daily versus asneeded corticosteroids for mild persistent asthma. N Engl J Med 2005;352:1519-28.

\title{
Beclomethasone and Albuterol in Mild Asthma
}

TO THE EDITOR: In the study of rescue use of beclomethasone and albuterol in a single inhaler for mild asthma reported by Papi et al. (May 17 issue), ${ }^{1}$ the morning peak expiratory flow rate (based on peak-flow diaries) was the primary end point, although there is enough reason to doubt its clinical relevance, its validity, and its physiological meaning in a disease that predominantly affects smaller airways. The peak expiratory flow rate reflects mainly central-airway mechanics ${ }^{2}$ and is insensitive for the monitoring of peripheral-airway patency. Only because no Bonferroni correction was used, the morning peak expiratory flow rate - but not the evening peak expiratory flow rate or variability in peak expiratory flow rate - was marginally significantly different $(\mathrm{P}=0.04)$ between the as-needed combination group and the as-needed albuterol group, whereas the secondary end points of forced expiratory volume in 1 second and forced vital capacity (percent of the predicted value) proved to be much more sensitive in detecting a treatment effect. A similar situation was reported previously, ${ }^{3}$ and the study by Papi et al. once again illustrates that measures of peak expiratory flow rate are insensitive and therefore, in my opinion, do not reflect the disease adequately.

PeterJ.F.M. Merkus, M.D., Ph.D.

Sophia Children's Hospital

3000 CB Rotterdam, the Netherlands

p.j.f.m.merkus@erasmusmc.nl

1. Papi A, Canonica GW, Maestrelli P, et al. Rescue use of beclomethasone and albuterol in a single inhaler for mild asthma. N Engl J Med 2007;356:2040-52.

2. Pedersen OF, Brackel HJL, Bogaard JM, Kerrebijn KF. Wavespeed-determined flow limitation at peak flow in normal and asthmatic subjects. J Appl Physiol 1997;83:1721-32.
3. Boushey HA, Sorkness CA, King TS, et al. Daily versus asneeded corticosteroids for mild persistent asthma. N Engl J Med 2005;352:1519-28.

TO THE EDITOR: The conclusions by Papi and colleagues with respect to the effectiveness and medication-sparing capacity of inhaled beclomethasone-albuterol as intermittent therapy for mild persistent asthma are based on their study of adults. The application of this method to children requires proof of principle. Lung growth, which affects treatment outcomes over time in children, could obviously not be accounted for in their study.

Luigi Terracciano, M.D.

Alessandro Fiocchi, M.D.

Gabriel R. Bouygue, M.Sc.

University of Milan Medical School

20129 Milan, Italy

allerg@tin.it

THE AUTHORS REPLY: Merkus is concerned that the use of the morning peak expiratory flow rate, based on peak-flow diaries, may be misleading because it is insensitive and may not reflect small-airway abnormalities. Measurement of the peak expiratory flow rate is still recommended in international guidelines ${ }^{1}$ for monitoring asthma. It is incorrect to state that the peak expiratory flow rate did not differ significantly between the groups in our study, since the morning peak expiratory flow rate was indeed sensitive enough to detect significant differences, in direct comparisons of the experimental treatment (as-needed use of combination albuterol-beclomethasone and regular use of beclomethasone) and the control treatment (as-needed 
use of albuterol). To the best of our knowledge, there is no single test of airway function that reflects the prevalent site of airflow obstruction in asthma, and there is no evidence from clinical trials that physiological measures that are thought to reflect peripheral airways correlate better with respiratory symptoms than other tests of airway function. ${ }^{2}$ We agree that since the objective of asthma treatment is to ensure clinical control, it would be of value to design trials that involve patientcentered outcomes. ${ }^{3}$

We also agree with Terracciano and colleagues that treatments for asthma should be tested in children with mild asthma. A randomized clinical trial sponsored by the National Heart, Lung, and Blood Institute is currently under way to address this important issue (the Childhood Asthma Research and Education [CARE] Network Trial - Treating Children to Prevent Exacerbations of Asthma [TREXA]; ClinicalTrials.gov number, NCT00394329).
Alberto Papi, M.D.

University of Ferrara

44100 Ferrara, Italy

Gabriele Nicolini, Pharm.D.

Chiesi Farmaceutici

43100 Parma, Italy

Leonardo M. Fabbri, M.D.

University of Modena and Reggio Emilia 41100 Modena, Italy

1. Global Initiative for Asthma. Global strategy for asthma management and prevention: NHLBI/WHO workshop report. Bethesda, MD: National Heart, Lung, and Blood Institute, 2005. (Updated 2006.)

2. Boulet LP. Comparative improvement of asthma symptoms and expiratory flows after corticosteroid treatment: a method to assess the effect of corticosteroids on large vs. small airways? Respir Med 2006;100:496-502.

3. Holgate ST, Bousquet J, Chung KF, et al. Summary of recommendations for the design of clinical trials and the registration of drugs used in the treatment of asthma. Respir Med 2004;98: 479-87.

\section{A National Survey of Physician-Industry Relationships}

TO THE EDITOR: Campbell et al. (April 26 issue) ${ }^{1}$ present disturbing evidence that many physicians accept inappropriate gifts from industry. Physicians should not accept such gifts, because the reciprocity they engender is known to affect prescribing decisions, which may harm patients and increase the cost of care.

The authors should have known, however, that an American Medical Association (AMA) policy has addressed the ethics regarding industry gifts to physicians since $1990,{ }^{2}$ more than a decade before the Pharmaceutical Research and Manufacturers of America (PhRMA) code was implemented in 2002. In fact, the PhRMA code was based largely on the AMA's opinion E-8.061, as even a cursory glance will show.

Many gifts cited by Campbell et al., such as reimbursement for admission and travel to continuing medical education (CME) meetings and tickets to cultural and sporting events, are clearly prohibited under the AMA code. The AMA calls on pharmaceutical companies and physicians to abide by their respective codes of conduct and to neither offer nor accept inappropriate gifts, for the benefit of patients and the public.

Robert M. Sade, M.D.

American Medical Association

Chicago, IL 60610

1. Campbell EG, Gruen RL, Mountford J, Miller LG, Cleary PD, Blumenthal D. A national survey of physician-industry relationships. N Engl J Med 2007;356:1742-50.

2. American Medical Association. Opinion E-8.061: gifts to physicians from industry. In: Code of medical ethics. Chicago: AMA Press, 2006:212-24.

TO THE EDITOR: Voluntary guidelines issued by the pharmaceutical industry in 2002 addressing interactions with health professionals include a ban on direct payments to physicians for attendance at CME or other conference events. According to the guidelines, any industry support for conferences or courses should be provided indirectly through event organizers. ${ }^{1}$ Despite this guideline, Campbell et al. state that $35 \%$ of the physicians in their survey reported receiving reimbursement for "costs of travel, time, meals, lodging, or other personal expenses for attending meetings," "free 